\title{
AVANÇOS TECNOLÓGICOS NO TRATAMENTO DE ÁGUAS DE MANANCIAIS
}

\section{TECHNOLOGICAL ADVANCES IN DRINKING WATER TREATMENT}

\author{
Adriana Correia de Velosa
}

Departamento de Engenharia Química - EP/ USP. Av. Prof. Lineu Prestes, 580, Bloco 18 - Conjunto das Químicas, Cidade Universitária, São Paulo, SP. E-mail: acvelosa@gmail.com

\begin{abstract}
RESUMO
A qualidade da água para consumo humano é decorrente da qualidade dos reservatórios que a mantém e também da qualidade do tratamento (químico e/ou físico) dado a ela, antes de sua distribuição à população. Água de má qualidade pode causar danos à saúde aumentando, por exemplo, a incidência de mortalidade infantil em regiões sem saneamento básico. Diversos processos físicos e químicos estão disponíveis no mercado para o tratamento da água e visam a retirada tanto de seres patógenos, bactérias e vírus, como dos chamados "contaminantes emergentes" que, embora ocorram em baixas concentrações, envolvem períodos de exposição prolongados. Estes podem vir a causar problemas de saúde como alterações hormonais, por exemplo. Neste trabalho são relatados os resultados de algumas das novas tecnologias de tratamento aplicadas em estações de tratamento de água ao redor do mundo.
\end{abstract}

Palavras-chave: Tratamento de água. Contaminantes emergentes. Ozônio. Ferrato. Dióxido de cloro.

\begin{abstract}
The quality of drinking water depends on the quality of the reservoirs and also on the quality of treatment (chemical and / or physical) it takes prior to distribution to the population. Poor water quality can cause damage to health - increasing the incidence of infant mortality in regions without sanitation, for example. Several physical and chemical processes are commercially available for water treatment. These processes aim pathogens removal, such as bacteria and viruses, as well as the so-called "emerging contaminants" removal, that in spite of occurring at very low concentrations in natural waters, involve prolonged human exposure becoming a health concern. New technologies have been developed in order to enhance the quality of drinking water and have been applied to different drinking water treatment plants around the world. The results of some technologies are discussed here.
\end{abstract}

Keywords: Water treatment. Emerging contaminants. Ozone. Ferrate. Chlorine dioxide 


\section{INTRODUÇÃO}

A mistura de águas provenientes de cursos de água poluídos aos mananciais que servem como fonte de abastecimento de água potável, causa um impacto negativo na qualidade e quantidade de água destes reservatórios. A água poluída é imprópria para consumo humano, banho, indústria ou agricultura e efetivamente reduz a quantidade de água disponível em determinada área, afetando diretamente os volumes disponíveis. Quanto maior o volume de água poluída, mais difícil seu tratamento para padrões aceitáveis, sendo necessários maiores gastos com energia e com reagentes químicos. Estes levam à geração de lodo residual que deverá ser descartado de modo adequado, de forma a evitar novas contaminações. Quanto pior a qualidade da água da fonte, maior o nível de tratamento necessário para alcançar um padrão aceitável e menor a qualidade da água tratada no final do processo.

Várias características do ambiente que estejam alteradas também podem afetar as quantidades disponíveis e a qualidade da água nos reservatórios. As superficies impermeáveis, que ocorrem em grandes cidades como São Paulo, reduzem a quantidade de água que infiltra nos aquíferos, afetando os fluxos básicos de ribeirões e aumentando o volume da mesma que escoa pela superfície. Isto criam fluxos mais erráticos e transportam maiores quantidades de contaminantes por lixiviação e lavagem do solo. Um grande aporte de metais pesados, em regiões urbanas e industrializadas e de defensivos agrícolas em regiões agrárias, é proveniente deste processo de lavagem, cuja água descarrega diretamente no reservatório em vez de ser filtrada no compartimento do solo, como aconteceria em regiões florestadas (ANA, 2011).

Em relação à presença de defensivos agrícolas em mananciais, o potencial de poluição está diretamente associado à forma de utilização desses produtos e aos fenômenos de transporte envolvidos, como drenagem do escoamento superficial de água de irrigação e águas pluviais e percolação no solo, o que compromete a qualidade da água subterrânea (SODRÉ, 2012).

Para os demais poluentes, existem outros fatores que têm influência direta sobre a sua presença nos corpos de água, destacando-se a existência de sistemas de coleta e tratamento de esgoto e também a eficiência de remoção dos poluentes presentes no esgoto.

Como a eficiência de remoção nos sistemas de tratamento de esgoto é desconhecida - ainda não existem informações precisas relacionadas a cada tipo de poluente potencialmente presente nos esgotos, seja pelos elevados custos das análises ou pela dificuldade de selecionar os parâmetros que devem ser avaliados diante da imensa quantidade de substâncias potencialmente perigosas - grande destaque é dado aos sistemas de coleta e tratamento de esgotos na poluição dos mananciais, uma vez que a maioria das substâncias químicas utilizadas diariamente tem como destino final os esgotos (SODRÉ, 2012).

No Brasil, dados de 2013 do Ministério das Cidades mostram que o atendimento em coleta de esgotos chega a apenas $46 \%$ da população e, do total de esgoto gerado, apenas $39 \%$ recebe algum tipo de tratamento, ou seja, além de não se saber a real eficiência do tratamento, este ainda é muito pouco aplicado em nosso país (MINISTERIO DAS CIDADES, 2013).

Uma outra fonte muito importante de poluição dos mananciais é o uso de agrotóxicos. Considerando que a agricultura é o setor que mais consome água doce no Brasil, cerca de 70\%, segundo o Fundo das Nações Unidas para Agricultura e Alimentação (FAO), pode-se dizer que além de sérios problemas para a saúde, os agrotóxicos também se transformaram em um grave problema ambiental no país (FAO, 2012).

Segundo a Agência Nacional de Vigilância Sanitária (ANVISA), o Brasil, atualmente, utiliza $19 \%$ de todo defensivo agrícola produzido no planeta, além disso, mais de $99 \%$ dos venenos aplicados nas lavouras não atingem a praga alvo, o que faz com que mais de $99 \%$ dos agrotóxicos vão parar nos rios, no solo, no ar e na água subterrânea, contaminando todas as fontes possíveis de abastecimento (ANVISA, 2012). 
De acordo com a hidrofobicidade ou lipofilicidade destes compostos, eles podem ser bioacumulados ao longo da cadeia alimentar chegando a alcançar concentrações perigosas em animais de topo de cadeia, como no caso de peixes que se alimentam de plantas contaminadas e outros pequenos peixes. Agrotóxicos como o DDT já foram encontrados no tecido adiposo de muitos peixes e até mesmo em leite materno (ALMEIDA et al., 2007).

Além dos poluentes químicos, os seres patógenos como vírus, bactérias e protozoários presentes na água de beber e provenientes da falta de saneamento básico, também acabam causando grandes problemas de saúde aumentando a incidência de mortalidade infantil, em regiões da América Latina onde não há suprimento de água de qualidade e saneamento, como apontam dados da OPAS (Organização Pan Americana de Saúde, 2012).

\section{PROBLEMAS ATUAIS DA POLUIÇÃO E CONTAMINAÇÃO DE ÁGUAS}

Os poluentes emergentes, químicos e biológicos, têm causado preocupação quanto ao impacto negativo na vida selvagem e na possível contaminação de pessoas. Dentre os contaminantes emergentes destacam-se os chamados disruptores endócrinos, que são compostos químicos capazes de interferir nas funções endócrinas normais, modulando ou rompendo mecanismos químicos hormonalmente regulados em organismos vivos, presentes em níveis de concentração traço e ultra-traço (ng. $L^{-1}$ ) (BEDDING et al, 1982, HEBERER, 2002).

A presença destes compostos em corpos de água naturais e em mananciais aumenta em grandes centros urbanos onde os aportes diários, de variados produtos químicos, são enorme. Fármacos, produtos de higiene pessoal, estrógenos sintéticos e naturais, subprodutos industriais e outras substâncias são comumente encontrados em efluentes e em corpos de água receptores de todo o mundo. No Brasil, embora ainda pouco estudado, há relatos da presença de fármacos como ácido acetilsalicílico, acetaminofeno e diclofenaco em águas superfíciais do rio Atibaia (Campinas, SP) e ainda, contaminação por cafeína, estigmastrol, estrona, 17 $\beta$-estradiol, bisfenol A e colesterol na água potável distribuída às residências da mesma cidade (LOCATELLI, 2011; MONTAGNER e JARDIM, 2011).

Apesar destes compostos aparecerem em concentrações muito baixas no meio ambiente, seu constante aporte pode levá-los a uma grande persistência e, embora possuam tempo de vida curtos, os efeitos na saúde decorrentes da exposição a estes compostos por longos períodos de tempo, além do potencial efeito sinérgico entre eles, necessitam ser estudados. Alguns estudos mostram que, dentre 5 antibióticoss estudados, a maior parte deles apresentou toxicidade moderada, porém ao se combinar estas substâncias entre si os efeitos tóxicos foram bem maiores (PLEITER et al., 2013). Diante disso, questões têm sido abordadas quanto ao risco da exposição humana por longos períodos a baixas concentrações de fármacos, seus metabólitos e produtos de degradação via uso de água potável.

STACKELBERG et al. (2007) fizeram importante estudo avaliando a eficiência da remoção de 113 poluentes orgânicos (fármacos, hidrocarbonetos poliaromáticos, detergentes, esteróides, pesticidas, plasticidas e outros) pelo tratamento tradicional para água potável e observaram resultados importantes. Os resultados mostraram que o tratamento convencional (clarificação por floculação com $\mathrm{FeCl}_{3}$, seguida por desinfecção com $\mathrm{NaClO}$ e filtração em carvão ativado) foi eficiente na remoção de contaminantes. De um modo geral, a filtração em carvão ativado foi responsável por cerca de $53 \%$, a desinfecção por $32 \%$ e a clarificação por $15 \%$ da remoção dos contaminantes da fase aquosa.

Os resultados indicaram também que há uma grande variabilidade quanto à eficiência de cada etapa do tratamento de acordo com o tipo do poluente orgânico. Embora alguns dos contaminantes orgânicos hidrofóbicos tenham sido oxidados pelo cloro na etapa de desinfecção, a 
maioria deles foi retirada por adsorção ao carvão ativado. Já para os compostos hidrofílicos (a maioria dos fármacos), a rota de remoção mais eficiente foi a oxidação pelo cloro livre. Mesmo com esta alta eficiência de remoção apontada por esse trabalho, cerca de 21 poluentes foram encontrados em pelo menos uma amostra de água ao final do tratamento e destes, somente o tetracloroetileno sofre regulação por agências ambientais ou de saúde.

Embora a concentração de alguns poluentes seja extremamente baixa (da ordem de ug/L) na água tratada, esta depende do bom funcionamento e, principalmente, do monitoramento das condições de adsorção do carvão ativado. Além disso, como foram monitorados apenas os poluentes na forma original, não se sabe a concentração dos compostos resultantes da oxidação parcial pelo cloro que, além de aumentar a hidrofilicidade e diminuir a retenção pela adsorção ao carvão ativado na etapa posterior, pode resultar na formação de um composto de toxicidade maior do que a do poluente inicial.

Considerando-se que nem todos os sistemas convencionais de tratamento possuem a etapa de adsorção em carvão ativado, responsável pela remoção da maior parte dos micropoluentes, o cenário da qualidade das águas potáveis tratadas é ainda mais preocupante e requer que novas técnicas sejam usadas. Técnicas estas para degradar e remover completamente todo e qualquer poluente e seus intermediários de degradação das águas dos mananciais. A seguir serão abordadas algumas técnicas que vêem sendo estudadas no mundo visando a destruição completa dos contaminantes.

\section{MÉTODOS DE TRATAMENTO DA ÁGUA}

\subsection{Tratamento convencional}

A água captada diretamente do manancial (rios ou lagos), denominada água bruta, é uma suspensão estável de partículas coloidais cujos movimentos são governados por difusão molecular. Estas partículas são retiradas da água pelo processo de coagulação no qual agentes químicos, como cloreto férrico ou algum polieletrólito, são adicionados ao tanque, desestabilizando-as durante o processo de agitação. Segue-se a isto o processo de floculação que promove a formação de partículas maiores (flocos) pela colisão dos colóides instáveis. A suspensão é então transferida para um tanque de sedimentação onde os flocos sofrem deposição (sedimentação) pela ação da gravidade e aquelas partículas que permanecem em suspensão serão retiradas do sistema por filtração. Após este procedimento, um desinfetante como o cloro é adicionado à água filtrada e reage por um certo tempo, após o qual a água é distribuída à população (Figura 1) (TOMPECK e JONES, 2006).

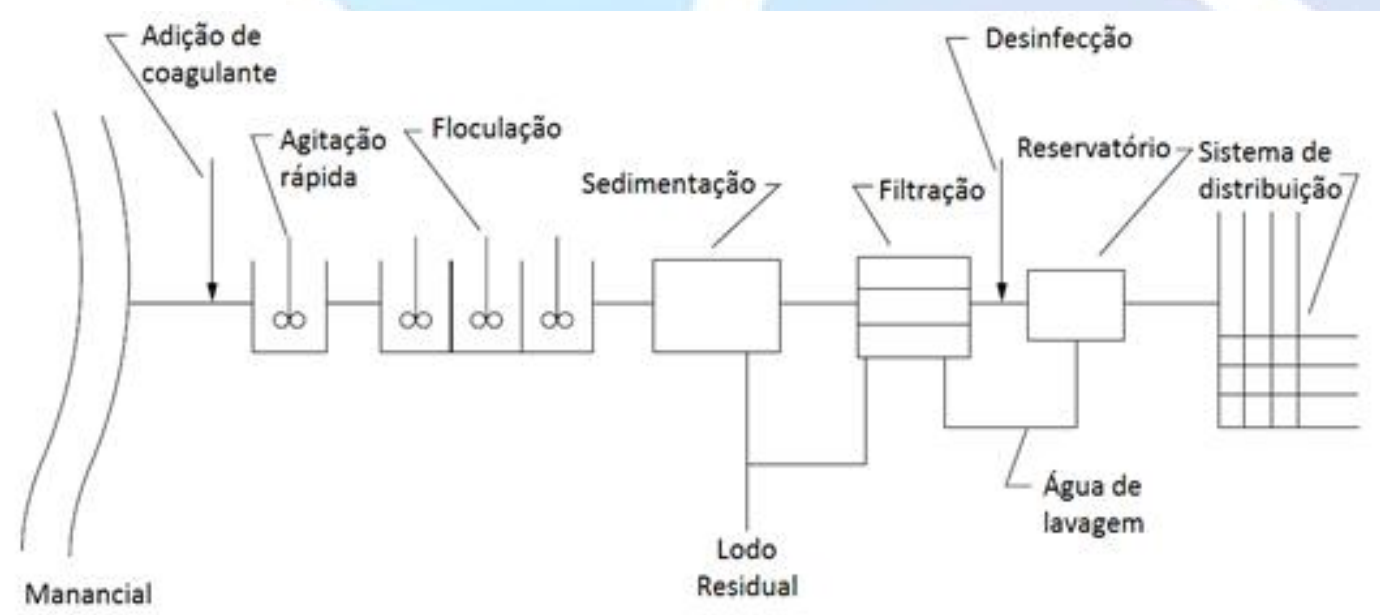

Figura 1. Esquema geral do tratamento convencional para água de abastecimento público. Fonte: (TOMPECK e JONES, 2006) 
Durante a etapa de desinfecção vários agentes físicos e/ou químicos podem ser usados para a destruição de micro-organismos e contaminantes químicos, sendo os principais ozônio, cloro, ultrafiltração e os processos oxidativos avançados como UV, UV-peróxido e Fenton. O ferrato e o dióxido de cloro têm surgido também como opção para esta etapa do tratamento e diversos trabalhos têm sido relatados sobre o emprego na degradação de contaminantes emergentes, como exposto adiante (ANQUANDAH et al., 2013, SHARMA et al., 2013).

\subsection{Ozônio}

A etapa de desinfecção pode ser realizada pela aplicação de processos químicos de oxidação, que são capazes de destruir completamente a maior parte dos poluentes orgânicos, gerando como produtos finais apenas água, $\mathrm{CO}_{2}$ e ácidos inorgânicos (dependendo da presença de cloro ou sulfato na molécula original do contaminante), evitando assim a formação de compostos clorados, como ocorrem com a desinfecção com cloro. Um destes processos é a ozonização.

$\mathrm{O}$ ozônio $\left(\mathrm{O}_{3}\right)$ é um dos desinfetantes e oxidantes mais fortes disponível para o tratamento de água. Ele deve ser gerado no local do tratamento e usado imediatamente, uma vez que o mesmo possui um tempo de vida muito curto ( $30 \mathrm{~min}$.). Isto faz com que o ozônio seja usado apenas como desinfetante primário, havendo a necessidade da aplicação de um segundo desinfetante para manter um efeito residual na rede de distribuição de água. Este gás pode ser aplicado em vários pontos do processo de tratamento de água, embora seja geralmente aplicado antes da coagulação (reduzindo a dremanda por coagulante) ou filtração (causando microfloculação e melhorando a filtrabilidade) (EPA, 2005).

A oxidação química usando ozônio tem-se mostrado um processo efetivo de tratamento para um amplo espectro de microcontaminantes orgânicos tanto para efluentes quanto para água potável, da bancada até escala completa. HUBER et al. (2005) mostraram em escala piloto que efluentes municipais contaminados com 11 diferentes tipos de fármacos e produtos de higiene pessoal foram oxidados em cerca de 90-99\%, por doses de ozônio que variaram entre 2 e $5 \mathrm{mg} \mathrm{O}_{3} \mathrm{~L}^{-1}$.

O uso de ozônio na inativação de micro-organismos também é reconhecido, apresentando uma relação entre as características morfológicas destes e a resistência ao gás, sendo proposta a seguinte ordem decrescente de resistência: fungos $>$ bactérias esporuladas > bactérias não esporuladas > vírus. Estudos realizados com bactérias Gram-positivas revelaram que a Staphylococcus aureus apresenta maior resistência em relação a Cândida albicans e Streptococcus feacali para o tratamento com ozônio (LEZCANO et al., 2001). No caso de bactérias Gramnegativas, Pseudomonas aeruginosa apresentou maior resistência em relação a Shigella sonnei, Salmonella typhimurium e Escherichia coli (LEZCANO et al, 1999). Ambos os estudos demonstraram que a inativação de bactérias corresponde a uma lei de velocidade de segunda ordem, dependendo da concentração de ozônio dissolvido e micro-organismos presentes.

Com base na desinfecção do vírus da poliomelite, a OMS lançou, na década de 70, um critério para o desenho de reatores para tratamento de água que estabelecia ser necessária uma concentração de $0,4 \mathrm{mg} . \mathrm{L}^{-1}$ de ozônio residual por um período de 4 minutos para inativar mais de 99,99\% deste vírus, critério este chamado de "virucida" (PADUA, 2009).

Outro critério adotado posteriormente (1989) pela USEPA levou em consideração a presença de "novos" micro-organismos nas águas de consumo, como os enterovírus, Legionella e cistos de Giardia. Este critério é baseado no conceito CT que especifica a concentração de ozônio dissolvido (mg.L ${ }^{-1}, \mathrm{C}$ ) e o tempo de contato efetivo (min, T) para cada micro-organismo encontrado na maioria das plantas de tratamento. Alguns valores de CT para diversos micro-organismos e diferentes processos de desinfecção são mostrados na tabela I (BATTALER et al., 2010).

Devido ao seu alto potencial de oxidação, o tratamento com ozônio tem sido amplamente usado em estações de tratamento de água potável para desinfecção, remoção de cor, controle de 
sabor e odor, diminuição da formação de subprodutos de desinfecção (clorados), aumento da biodegradabilidade e degradação de inúmeros compostos orgânicos.

O ozônio é instável em água, sendo que o $\mathrm{pH}$, temperatura, as características da água, como alcalinidade e matéria orgânica, e a dose de ozônio influenciam fortemente a degradação dos micropoluentes. A completa compreensão dos mecanismos de influência, no entanto, são ainda desconhecidos.

A decomposição do ozônio em águas naturais é caracterizada por uma rápida diminuição da concentração inicial, seguida de uma segunda fase na qual a concentração de ozônio diminui de acordo com uma cinética de primeira ordem, sendo que o principal produto de decomposição do ozônio é o radical hidroxila $\left({ }^{\bullet} \mathrm{OH}\right)$, que tem um potencial de oxidação maior do que a do ozônio ( $\mathrm{E}^{0}$ $=2,8 \mathrm{~V} \mathrm{x} \mathrm{E} \mathrm{E}^{0}=2,06 \mathrm{~V}$ ) sendo, portanto, oxidante ainda mais forte (ALMEIDA et al., 2004).

Dependendo da qualidade do meio em que se encontra, o tempo de meia vida do ozônio varia de alguns segundos até horas. A estabilidade deste no meio depende de diversos fatores, sendo o pH aquele que merece especial atenção, uma vez que os íons hidroxila iniciam o processo de decomposição do ozônio, como mostrado nas equações 1 e 2 .

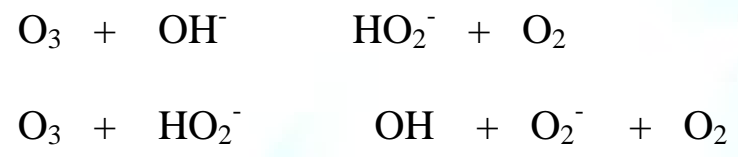

Tabela 1 - Valores de CT para inativação de $2 \log$

\begin{tabular}{|c|c|c|c|c|}
\hline \multirow{3}{*}{ Micro-organismo } & \multicolumn{4}{|c|}{$\begin{array}{l}\text { Processo } \\
\text { pH }\end{array}$} \\
\hline & $\begin{array}{c}\text { Cloro livre } \\
\text { 6-7 }\end{array}$ & $\begin{array}{c}\text { Cloramina } \\
8-9\end{array}$ & $\begin{array}{l}\text { Dióxido de } \\
\text { cloro } \\
6-7\end{array}$ & $\begin{array}{c}\text { Ozônio } \\
\text { 6-7 }\end{array}$ \\
\hline & \multicolumn{4}{|c|}{$\mathrm{CT}(\mathrm{mg} / \mathrm{min} / \mathrm{L})$} \\
\hline E. coli & $0,034-0,05$ & $95-180$ & $0,4-0,75$ & 0,02 \\
\hline Polio vírus & $1,1-2,5$ & $768-3740$ & $0,2-6,7$ & $0,1-0,2$ \\
\hline Rotavirus & $0,01-0,05$ & $3800-6500$ & $0,2-2,1$ & $0,006-0,06$ \\
\hline Giardia lamblia (cistos) & $47-150$ & 2200 & 26 & $0,5-0,6$ \\
\hline Giardia muris (cistos) & $30-630$ & 1400 & $7,2-18,5$ & $1,8-2,0$ \\
\hline Cryptosporidium parvum & 7200 & $7200 *$ & $78 *$ & $5-10^{*}$ \\
\hline $\begin{array}{c}\text { Cryptosporidium parvum } \\
\left(1^{\circ} \mathrm{C}\right)\end{array}$ & & & 200 & 10 \\
\hline $\begin{array}{c}\text { Cryptosporidium parvum } \\
\left(22^{\circ} \mathrm{C}\right)\end{array}$ & & & $120 * *$ & $7 * *$ \\
\hline
\end{tabular}


A oxidação de compostos orgânicos e inorgânicos durante a ozonização pode ocorrer tanto via ozônio molecular (reação direta - predominante em meio acido), quanto pelo radical hidroxila (reação indireta - predominante em meio alcalino), embora na prática os dois mecanismos ocorram concomitantemente. A reação direta (ataque eletrofílico pelo ozônio molecular) é atribuída aos compostos que contêm ligações do tipo $\mathrm{C}=\mathrm{C}$ (alcenos), grupos funcionais específicos $\left(\mathrm{OH}, \mathrm{CH}_{3}\right.$, $\left.\mathrm{OCH}_{3}\right)$ e átomos que apresentam densidade de carga negativa $(\mathrm{N}, \mathrm{P}, \mathrm{O}$ e $\mathrm{S})$. A reação indireta é não seletiva, sendo capaz de promover um ataque a compostos orgânicos $10^{6}-10^{9}$ vezes mais rápido do que oxidantes como o $\mathrm{H}_{2} \mathrm{O}_{2}$ e o próprio $\mathrm{O}_{3}$. Os processos de oxidação podem ocorrer tanto por meio do ozônio molecular como do radical hidroxila, já os processos de desinfecção ocorrem predominantemente via ozônio molecular (ALMEIDA et al., 2004).

Além do $\mathrm{pH}$, outros parâmetros de qualidade da água podem impactar a ozonização e manutenção residual de ozônio. A turbidez, cor e matéria orgânica consomem o ozônio aumentando sua demanda, assim como a presença de ferro e do manganês. O monitoramento de tais parâmetros na água a ser tratada é de extrema importância para o efetivo processo de desinfecção, de modo a evitar o uso de uma dose de ozônio menor do que a necessária para a destruição dos contaminantes orgânicos e/ ou microbiológicos.

\subsection{Cloro e derivados}

$\mathrm{O}$ cloro $\left(\mathrm{Cl}_{2}\right)$ é um agente oxidante forte usado no tratamento de água para oxidação e desinfecção. Como oxidante, o cloro é aplicado para controlar o crescimento biológico e remover compostos que dão cor, odor e sabor à água, além do ferro, manganês e outros compostos inorgânicos aí presentes, como o arsênio. O cloro pode ainda ser usado como desinfetante primário, tendo ação de desinfecção durante o tratamento da água, e também ação residual, em que promove o controle da proliferação microbiana ao longo da rede de distribuição - ou apenas como desinfetante secundário, aplicado após o uso de outras tecnologias de desinfecção como o ozônio, radiação UV ou dióxido de cloro (PÁDUA, 2009).

O cloro está disponível como gás comprimido $\left(\mathrm{Cl}_{2}\right)$, como solução de hipoclorito de sódio $(\mathrm{NaOCl})$ ou como um sólido de hipoclorito de cálcio $\left(\mathrm{Ca}(\mathrm{OCl})_{2}\right)$. Todas as formas de cloro, quando aplicadas em água, geram o ácido hipocloroso $(\mathrm{HOCl})$ que, em pHs entre 6 e 9, se dissocia liberando os íons hipoclorito $\left(\mathrm{OCl}^{-}\right)$e hidrogênio $\left(\mathrm{H}^{+}\right)$. $\mathrm{O} \mathrm{pH}$ da água irá então determinar a espécie dominante que será $\mathrm{HOCl}$ em meios mais ácidos e $\mathrm{OCl}^{-}$em meios mais básicos, sendo que das duas espécies químicas o ácido hipocloroso é o agente oxidante mais forte, sendo também as duas espécies denominadas como cloro livre (TOMPECK e JONES, 2006).

Assim como ocorre com o ozônio, o cloro também necessita ficar um certo tempo em contato com a água para tratá-la (CT), e este tempo varia de acordo com a concentração de cloro, $\mathrm{pH}$ e temperatura. $\mathrm{O}$ aumento de $\mathrm{CT}$, entretanto, pode causar um efeito indesejado uma vez que ocorre a formação de subprodutos de desinfecção, que são compostos organoclorados suspeitos de serem carcerígenos. Estes compostos surgem da reação entre o cloro e a matéria orgânica natural presentes nas águas naturais, sendo que os principais deles, chamados de trihalometanos, são o clorofórmio, o bromodiclorometano, o dibromomonoclorometano e o bromofórmio (ALKHATIB e PETERS, 2008; PASCHOALATO et al., 2008; LOU, 2010).

Um modo alternativo de se conseguir a desinfecção e evitar a formação dos subprodutos tóxicos é impedindo o cloro residual na água de distribuição, o que geralmente é feito para inibir a contaminação por micro-organismos ao longo da rede de distribuição, após o processo de desinfecção. Neste caso aplicar-se-ia a amônia $\left(\mathrm{NH}_{3}\right)$, cuja reação com o cloro livre $\left(\mathrm{Cl}_{2}\right)$ leva à formação das cloraminas - monocloroamina $\left(\mathrm{NH}_{2} \mathrm{Cl}\right)$, dicloroamina $\left(\mathrm{NHCl}_{2}\right)$ e tricloroamina $\left(\mathrm{NCl}_{3}\right)$, que também agem como agentes desinfectantes, porém com menor formação de compostos organoclorados, principalmente trihalometanos e ácidos acéticos halogenados (TIAN et al., 2013). 
A relativa concentração final desses compostos dependerá do $\mathrm{pH}$ da água e da proporção relativa de cloro e amônia. Em relações de massa cloro:amônia de 3:1 até 5:1 $\left(\mathrm{Cl}_{2}: \mathrm{NH}_{3}-\mathrm{N}\right)$ e em pHs neutros, que são condições comuns no tratamento de água potável, o principal composto formado no meio é a monocloroamina. Em pH 7 e abaixo desse valor, a monocloroamina é cerca de 200 vezes menos efetiva na inativação de coliformes fecais, nas mesmas condições de tempo de reação, temperatura e $\mathrm{pH}$, do que o cloro livre, sendo necessárias doses 25 vezes maiores para a obtenção da mesma eficiência na inativação de bactérias. A dicloroamina parece ser duas vezes mais eficiente do que a monocloroamina, entretanto, ela leva a problemas como a formação de cor e sabor e é, portanto, evitada (MEYER, 1994).

O uso da monocloroamina, não só para manutenção da água de distribuição, mas durante o processo de desinfecção também é eficiente. Quando o cloro e a amônia são adicionados simultaneamente, uma boa agitação pode reduzir o tempo em que o cloro livre fica em contato com os compostos orgânicos dissolvidos na água, diminuindo assim a possibilidade de formação de subprodutos da desinfecção (compostos organoclorados).

O Cryptosporidium, um parasita protozoário, é um patógeno altamente resistente à inativação por cloro ou cloraminas, de modo que a inclusão do parâmetro de sua análise periódica no Brasil, por meio da Portaria 2914/ 2012 do Ministério da Saúde, dá um importante passo em direção à mudança nos métodos de tratamento de água no Brasil, uma vez que a imensa maioria dos Estados e Municípios faz uso do tratamento convencional (com o uso do cloro como desinfectante primário) (PADUA, 2009).

Embora alguns trabalhos apontem para uma maior eficiência de remoção de cianobactérias (grandes florações são periodicamente encontradas em grandes reservatórios como Billings ou Barra Bonita, ambos no estado de São Paulo) pelos processos de filtração ou sedimentação com o uso de cloro em uma etapa anterior a estes processos (pré-oxidação), este tipo de aplicação do cloro não é recomendado, visto que o cloro causa a lise das cianobactérias liberando para a água grandes quantidades de toxinas neuro e hepatotóxicas que não são removidas pelos processos posteriores de coagulação e filtração (MEYER, 1994).

O ozônio, embora necessite de doses mais elevadas para causar a lise das bactérias, também leva à liberação de tais toxinas para a água. Neste caso, aumentando-se a dose de ozônio, conseguese degradar as moléculas de toxinas, entretanto o uso da pré-oxidação em águas brutas deve ser cuidadosamente monitorado uma vez que, embora cause a diminuição da quantidade de cianobactérias, também pode elevar a quantidade de toxinas na água tratada, dependendo da dose (BATTALER et al., 2010).

\subsection{Radiação ultravioleta (UV)}

O uso de radiação UV na desinfecção de água para abastecimento tem sido amplamente aplicada na Europa e tem ganhado grande atenção nos Estados Unidos, depois que experimentos mostrando a inativação de Cryptosporidium com baixas doses de radiação e a não formação de subprodutos de desinfecção durante o processo foram publicados (ROSENFELDT, 2011).

O uso da radiação UV no lugar do ozônio como processo oxidativo avançado é uma opção atrativa pelo menor custo e pela capacidade de promover a degradação total de compostos orgânicos, gerando menos subprodutos de oxidação. A radiação UV é aquela que apresenta comprimentos de onda entre 100 e $400 \mathrm{~nm}$. Quando esta se encontra entre 400 e $315 \mathrm{~nm}$ é chamada de UVA, entre 315 e $280 \mathrm{~nm}$ UVB e entre 280 e $100 \mathrm{~nm}$ de UVC. Com o propósito de oxidar os compostos orgânicos refratários à oxidação por cloro, por exemplo, ou de desinfectar a água de abastecimento, são utilizadas lâmpadas de mercúrio de baixa pressão com emissão centrada em 254 $\mathrm{nm}$, radiação UVC, conhecidas por lâmpadas germicidas.

Para que um composto seja fotolábil (possa sofrer fotólise), este deve ter a capacidade de absorver luz e como consequência desta absorção ocorre então uma transformação química. $\mathrm{O}$ 
mecanismo de ação pelo qual a radiação destrói as moléculas orgânicas e os seres patógenos pode ser por via direta, fotólise (quebra) do composto alvo, ou por via indireta, no qual um segundo composto é excitado e transfere sua energia para a molécula alvo (aquela que se quer destruir) ou para uma molécula de oxigênio presente no meio, causando a geração de radicais livres, como o radical hidroxila $\left({ }^{\bullet} \mathrm{OH}\right)$, que irão atacar e destruir qualquer composto orgânico presente na água (BELTRAN, 2003).

Neste segundo caso encontra-se o processo combinado de tratamento de água que usa a radiação UV e o peróxido de hidrogênio $\left(\mathrm{H}_{2} \mathrm{O}_{2}\right)$, que reagem segundo a equação 3 .

$$
\mathrm{H}_{2} \mathrm{O}_{2}+\mathrm{h} v \rightarrow{ }^{\bullet} \mathrm{OH}
$$

A partir desta reação são produzidos radicais hidroxila que irão atuar como espécies altamente oxidantes da matéria orgânica presente na água, degradando os contaminantes assim como destruindo os micro-organismos existentes. Pelo fato da molécula de peróxido de hidrogênio, entretanto, ter baixa absorção na região UV do espectro de radiação (principalmente em $254 \mathrm{~nm}$, que é o máximo de emissão das lâmpadas germicidas geralmente usadas), são necessárias altas doses deste composto para uma ação efetiva na geração de radicais hidroxila. Isto fará com que, após o tratamento, o excesso de peróxido deva ser retirado da água para sua posterior distribuição (BELTRAN, 2003). Assim, como no caso do ozônio e do cloro, também existe uma dose mínima de radiação UV que deve ser fornecida para degradar os diferentes tipos de compostos químicos e para os diferentes micro-organismos.

Quando a radiação UV é aplicada em um micro-organismo, o material genético da célula absorve energia e sua estrutura é alterada (mutação), interferindo no processo de replicação do organismo e dificultando a reprodução do mesmo. A dose de radiação UV necessária para a inativação dos micro-organismos varia de espécie para espécie e, embora a inativação aumente com o aumento da dose, este aumento nem sempre segue uma relação log-linear típica.

Dentre os patógenos de interesse na água potável, os vírus são os mais resistentes à radiação UV, seguidos pelas bactérias e protozoários. Na Tabela 2 é possível observar a dose de radiação UV mínima para a inativação de Cryptosporidium, Giardia e vírus estipuladas pela EPA. Geralmente as doses aplicadas são de 2 a 4 vezes maiores do que as doses mínimas considerando-se um fator de segurança, fator este baseado no fato de alguns micro-organismos possuírem mecanismos enzimáticos de recuperação de sua replicação e potencial reativação (BETANCOURT e ROSE, 2004; QUEK e HU, 2008).

Tabela 2 - Doses mínimas de radiação UV para a inativação de alguns patógenos

\begin{tabular}{c|c|c|c|c|c|c|c|c}
\hline & \multicolumn{7}{|c}{ Inativação Log } \\
\cline { 2 - 10 } & $\mathbf{0 , 5}$ & $\mathbf{1 , 0}$ & $\mathbf{1 , 5}$ & $\mathbf{2 , 0}$ & $\mathbf{2 , 5}$ & $\mathbf{3 , 0}$ & $\mathbf{3 , 5}$ & $\mathbf{4 , 0}$ \\
\hline Cryptosporidium & 1,6 & 2,5 & 3,9 & 5,8 & 8,5 & 11,7 & - & - \\
\hline Giardia & 1,5 & 2,1 & 3,0 & 5,2 & 7,7 & 10,8 & - & - \\
\hline vírus & 39,4 & 58,1 & 79,1 & 100,1 & 120,7 & 142,6 & 163,1 & 186,0 \\
\hline
\end{tabular}

Valores de dose em $\mathrm{mJ} / \mathrm{cm}^{2}$

O uso da radiação UV pode ser influenciado por alguns fatores, como por exemplo, pela presença de partículas em suspensão (turbidez). Essas partículas podem absorver ou espalhar a radiação, diminuindo a intensidade de luz que chega aos micro-organismos, e são de composição e 
tamanhos diversos, incluindo grandes moléculas, micro-organismos, argilas e algas. Além disso, os micróbios associados à partículas suspensas podem ser protegidos da radiação pelas mesmas, reduzindo assim a eficiência da desinfecção (WOLFE, 1990).

Outro fator que tem grande influência na eficiência do processo de desinfecção é a quantidade de matéria orgânica dissolvida na água. Esta matéria orgânica é capaz de absorver radiação UV levando à necessidade de maior irradiância, ou então de maior tempo de exposição da água à radiação UV, para se obter o mesmo nível de inativação que a mesma água com menor quantidade de matéria orgânica dissolvida. Se a quantidade de matéria orgânica presente na água bruta for muito grande, é recomendado que a radiação UV seja aplicada apenas após a remoção desta por algum processo como a coagulação ou filtração em carvão ativado.

\subsection{Separação por membranas}

Membranas são materiais que agem como barreiras seletivas, barrando determinados compostos e permitindo a passagem de outros. Existem 4 categorias de processos usando membranas que são impulsionados por pressão: microfiltração (MF), ultrafiltração (UF), nanofiltração (NF) e osmose reversa (OR) (ZHOU e SMITH, 2001).

Processos de baixa pressão, como a microfiltração e ultrafiltração, são aplicados tipicamente na remoção de material particulado e micróbios (na sequência de uma filtração granular média ou em substituição a esta), podendo ser operados sob pressão positiva ou negativa (vácuo). Já os processos de mais alta pressão (NF e $\mathrm{OR}$ ) são usados tipicamente na remoção de contaminantes orgânicos ou inorgânicos dissolvidos na água.

Os mecanismos potenciais de ação das membranas de baixa pressão incluem: (i) peneiramento ou exclusão por tamanho, (ii) a adsorção à superfície da membrana ou em sua estrutura interna, (iii) adsorção às partículas presentes na água de alimentação e remoção subsequente pela membrana, (iv) remoção pela adesão à camada formada por material retido na superfície da membrana, (v) remoção por adesão nas incrustações da membrana que não são reversíveis hidraulicamente.O mecanismo de remoção dependerá do microrganismo e a química da solução a ser filtrada (BETANCOURT e ROSE, 2004)

A natureza do material que compõe a membrana (poliamida, amida, acetato de celulose) influencia o mecanismo de retenção, sendo que a presença de matéria orgânica favorece a remoção de certos agrotóxicos, como a atrazina e a simazina, por exemplo, pelo processo de fisiosorção e quimiosorção.

A habilidade de determinada membrana em reter determinado material/ composto está diretamente ligada ao seu tamanho de poro ou ao seu peso molecular de corte. O peso molecular de corte é uma especificação do fabricante e se refere à massa molecular de um macrosoluto (glicol ou proteína, por exemplo) para o qual uma membrana tem uma capacidade de retenção superior a 90 por cento. Já o tamanho de poro se refere ao diâmetro dos microporos presentes na superfície da membrana (EPA, 2005). A denominação dos tipos de filtração provêm da faixa de tamanho dos poros presentes em suas membranas, conforme Figura 2. 


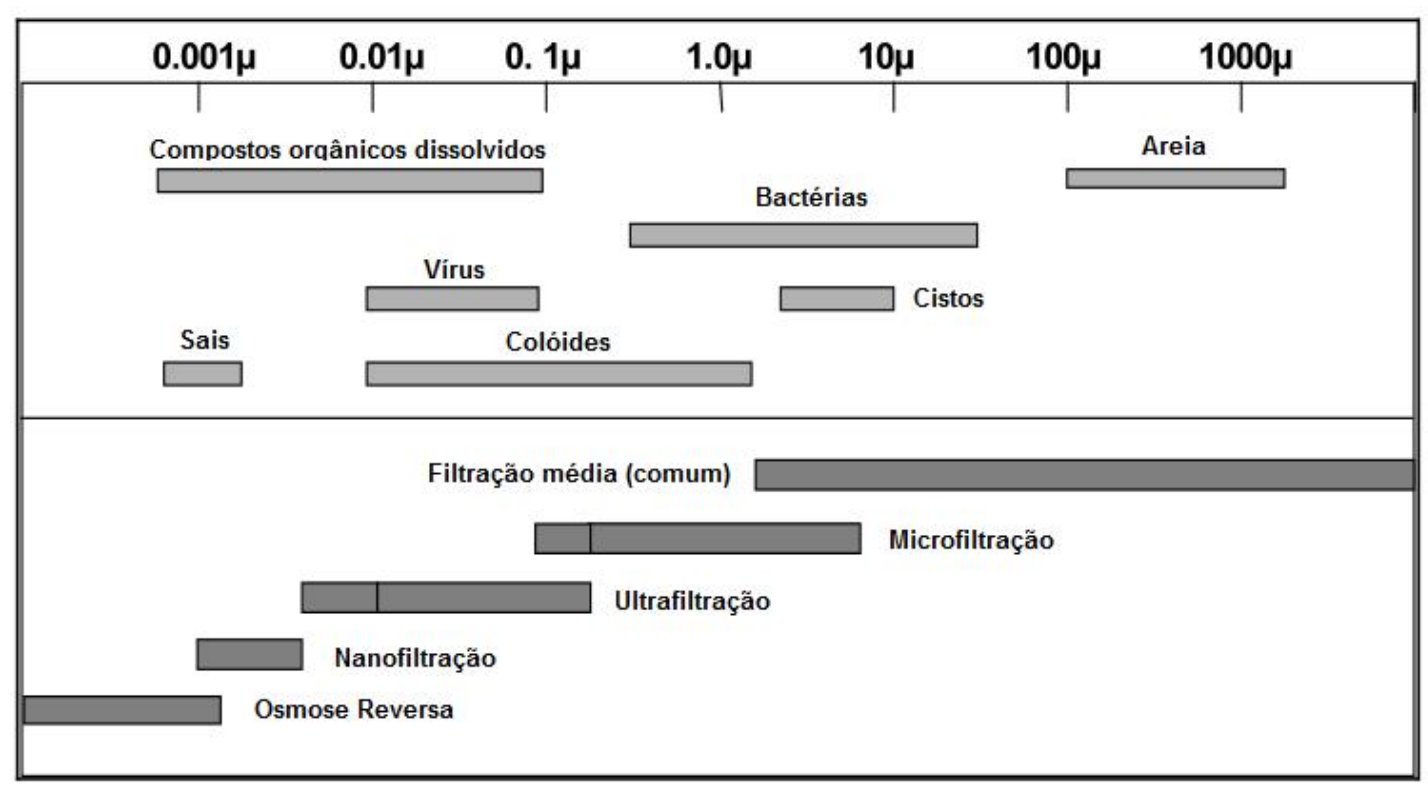

Figura 2 - Tipos de filtração por membranas usadas no tratamento de água e seus tamanhos de poro em micrômetros. Fonte: Adaptado de EPA (2005).

Os sistemas de MF e UF são capazes de promover remoções log significantes de bactérias, cistos de Giardia e oocistos de Cryptosporidium. As remoções de bactérias chegam a $9 \log$ e as de Giardia e Cryptosporidium chegam a mais de 8 log. Para vírus, entretanto, a remoção por MF alcança cerca de $3 \log$, no máximo, sendo uma média reportada de $1 \log$ e a UF promove a remoção dos vírus ao seu limite de detecção (EPA, 2005).

A filtração por OR é baseada no princípio da osmose, no qual uma membrana separando duas soluções aquosas de diferentes concentrações permite a passagem de água para o lado mais concentrado, de modo que a concentração dos dois lados da membrana se equiparem. No caso da OR, pressão é aplicada no lado mais concentrado da membrana fazendo com que a água flua para o lado mais diluído, deixando para trás os contaminantes da água. A aplicação deste processo teve início na década de 1960 na dessalinização da água do mar para geração de "água doce"

A MF e a UF têm mostrado excelentes resultados quanto à remoção de turbidez, material particulado e micro-organismos, porém, como o tamanho dos poros das membranas varia dentre os diferentes tipos de membranas e também a forma e o tamanho dos diversos micro-organismos diferem entre si, a capacidade de remoção de um micro-organismo em particular pode variar. Tanto a MF quanto a UF possuem, no entanto, uma capacidade de desinfecção maior que os meios tradicionais de filtração. A ultrafiltração também já foi apontada como opção para o tratamento de águas poluídas com o bisfenol $\mathrm{A}$, um poluente emergente que age como interferente endócrino (BING-ZHI, 2008).

Uma variável muito importante para a planta de tratamento de água, que deve ser levada em consideração quando se pretende usar membranas de filtração, é o fluxo de água a ser tratado, uma vez que este é um dos parâmetros que determinará o custo do projeto. Aumentando-se o fluxo de água que passa pela membrana pode-se diminuir o custo relativo ao tamanho do filtro. O custo com a energia gasta pra suprir a maior pressão necessária para a passagem de maior quantidade de água, entretanto, também aumenta, incrementando os custos com a maior frequência de limpeza da membrana e o potencial acréscim da frequência de trocas da mesma (EPA, 2005).

MIERZWA et al. (2008) realizaram estudo de custos de implantação e operação de um sistema de tratamento de água por Ultrafiltração em uma unidade piloto junto à represa de Guarapiranga, na cidade de São Paulo, e observaram que, comparado-se ao sistema convencional de 
tratamento de água, a UF tem custo duas vezes maior. Porém, ao se comparar ao custo do sistema convencional seguido da filtração em carvão ativado, que é necessário para se obter o mesmo grau de pureza de água obtido pela UF, os valores passam a ser bem próximos, tornando o sistema de UF em um tratamento bastante competitivo.

\subsection{Ferrato}

O Ferrato (Fe (VI)) é um agente oxidante razoavelmente forte, com potencial de oxidação de 2,20 V em meio ácido e de $0,70 \mathrm{~V}$ em meios básicos, e que tem sido recentemente usado em estações de tratamento de água para retirada de contaminantes orgânicos e inorgânicos. No ferrato (Fe(VI)) as ligações oxigênio-ferro são equivalentes e possuem um grande caráter covalente, o que explica a baixa taxa de troca dos ligantes óxidos por moléculas de água (LI et al., 2005; SHARMA, 2013).

Uma característica própria do íon ferrato é a maneira pela qual decai para $\mathrm{Fe}(\mathrm{III})$ e $\mathrm{O}_{2}$ em solução, que é uma reação predominantemente de segunda ordem e fortemente dependente do $\mathrm{pH}$ da solução. Assim, o ferrato apresenta maior estabilidade em água em $\mathrm{pH} 10$, porém é menos reativo devido ao menor potencial de oxidação. Já em condições ácidas $(\mathrm{pH}<6)$ ocorre um rápido decaimento pela reação com a água (equação 4), devido ao alto potencial redox apresentado nestas condições (GRAHAM et al., 2004).

$4 \mathrm{~K}_{2} \mathrm{FeO}_{4}+10 \mathrm{H}_{2} \mathrm{O} \rightarrow 4 \mathrm{Fe}(\mathrm{OH})_{3}+8 \mathrm{KOH}+3 \mathrm{O}_{2}$

O íon ferrato é um oxidante seletivo capaz de oxidar diversos grupamentos funcionais como os álcoois primários e secundários - gerando, respectivamente, aldeídos e cetonas - além de aminas primárias e compostos de enxofre (SHARMA, 2013).

GRAHAM et al. (2004) estudaram a influência do pH na degradação de fenóis clorados e também de tricloroetileno e observaram que no caso dos fenóis, o pH ótimo variou de acordo com o pKa do composto, uma vez que as desprotonadas são mais reativas, e no caso do TCE o pH ótimo encontrado foi em torno de 8 , sendo este resultado atribuído ao comportamento redox do ferrato (GRAHAM et al., 2004).

A degradação de alguns hormônios (estrona, $17 \beta$-estradiol e $17 \alpha$-etinilestradiol) por ferrato também foi estudada. Neste caso, os resultados sugerem que o $\mathrm{pH} 9$ é o mais favorável para maior eficiência de remoção e a completa remoção dos compostos foi obtida quando a razão molar maior que 3: 1 (ferrato: hormônios) foi aplicada (YANG et al., 2012).

No caso da degradação da ampicilina e da amoxicilina pelo ferrato, observou-se que a oxidação deve ocorrer primariamente nos grupamentos de amina primária e secundária presentes na molécula, uma vez que as constantes de velocidade obtidas para tais compostos se assemelham às obtidas para a glicina e a dimetilamina. O grupamento fenólico presente na amoxicilina causou pequeno aumento em sua reatividade, porém não mostrou qualquer influência na reatividade em função do pH da reação (SHARMA et al., 2013).

Um recente e vasto trabalho aplicando o ferrato para degradação de substâncias desreguladoras endócrinas e fármacos em efluente de estação de tratamento de águas residuárias apontou a eficiência na remoção de diversos compostos, entretanto, também mostrou que tal tratamento é ineficiente na degradação de triclocarban, epi-androsterona, androsterona, 5 $\alpha$ dihidrotestosterona, ácido clofíbrico, ácido 2,4-dichlorofenoxiacético, ácido 2-metil-4clorofenoxiacético, ibuprofeno, fenoprofeno, gemfibrozil, cetoprofeno, primidona, ciclofosfamida e eritromicina- $\mathrm{H}_{2} \mathrm{O}$. Esse resultado é muito importante, pois mostra algumas limitações de tratamento encontradas para a aplicação do ferrato que, apesar de ser um método interessante por atuar também como agente coagulante em estações de tratamento de água, não é um oxidante universal tal como o radical hidroxila (LEE e von GUNTEN, 2010). 


\subsection{Dióxido de cloro}

O dióxido de cloro $\left(\mathrm{ClO}_{2}\right)$ é considerado radical estável $(\mathrm{O}=\mathrm{Cl}=\mathrm{O})$ e tem sido aplicado como oxidante em diversos processos como o branqueamento de celulose, tratamento de efluentes e água potável, assim como sua desinfecção (HOIGNÉ e BADER, 1994). O dióxido de cloro tem sido usado em estações de tratamento de água no Brasil, em plantas operadas pela SANEPAR, e no mundo devido à menor produção de compostos organoclorados quando comparado com a desinfecção por cloro.

Reagindo como aceptor de elétrons, $\mathrm{o} \mathrm{ClO}_{2}$ não substitui os átomos de hidrogênio presentes em ligações do tipo C-H e N-H, presentes na matéria orgânica, por átomos de cloro. Além disso, ao contrário do cloro aquoso $\left(\mathrm{HOCl} / \mathrm{ClO}^{-}\right)$, seu poder de desinfecção não é influenciado pelo $\mathrm{pH}$ do meio ou pela presença de amônia, não sendo também capaz de oxidar o brometo com consequente geração de bromo (HOIGNÉ e BADER, 1994; HEY et al., 2012).

Existe uma forte limitação, no entanto, quanto à dosagem do dióxido de cloro no tratamento de água potável uma vez que seu principal produto de reação é o clorito, que é considerado um veneno. Deste modo, dosagens típicas para o tratamento de águas variam entre 0,04 e 0,4 mg.L $\mathrm{L}^{-1}$. Em tão baixas concentrações o tempo de vida do dióxido de cloro aquoso irá depender da qualidade da água a ser tratada e, geralmente, este oxidante é aplicado apenas após uma pré oxidação ou então quando a qualidade da água bruta é boa (HOIGNÉ e BADER, 1994).

LEE e von GUNTEN (2010) estudaram a cinética de degradação de diversos micropoluentes, como antibióticos e hormônios, por diferentes agentes oxidantes, dentre eles o dióxido de cloro, o ferrato e o radical hidroxila, em matriz de água de uma estação de tratamento. Nesta matriz, que apresentava cerca de 5 ppm de carbono, a cinética de decaimento do dióxido de cloro seguiu duas fases distintas: uma rápida ( 2 minutos iniciais), causada provavelmente pela reação com grupamentos fenólicos e com anilinas, e uma lenta (que se estendeu além de 60 minutos), causada pela reação com aminas secundárias e terciárias.

Nas condições estudadas no artigo, o dióxido de cloro foi capaz de degradar o $17 \alpha$ etinilestradiol e o sulfametoxazol, sendo ineficiente, porém quanto à degradação da carbamazepina, atenolol e ibuprofeno. O radical hidroxila, por ser um oxidante não seletivo, conseguiu oxidar todos os compostos estudados, entretanto, como ele também reage indistintamente com a matéria orgânica presente, houve a necessidade de uma dose muito maior de ${ }^{\circ} \mathrm{OH}$ do que de $\mathrm{ClO}_{2}$ para se alcançar a mesma porcentagem de degradação dos fármacos (LEE e von GUNTEN, 2010).

Hoigné e Bader (1994) estudaram a cinética de reação entre o $\mathrm{ClO}_{2}$ e compostos orgânicos e inorgânicos no contex to do tratamento de águas e relataram que, de uma maneira geral, as taxas de reação são altas para nitrito, iodeto, Fe(II), e, quando o pH não está muito baixo, para fenóis, aminas terciárias e tióis. Já o brometo, amônia, alcenos, hidrocarbonetos aromáticos, aminas primárias e secundárias, aldeídos, cetonas e carboidratos não são reativos com o $\mathrm{ClO}_{2}$.

\section{CONCLUSÕES}

Atualmente existem diversas tecnologias disponíveis para o tratamento de água. A implementação de uma ou de outra tecnologia irá depender basicamente das condições da água bruta a ser tratada, dos tipos de contaminantes e concentração e das restrições impostas pela legislação vigente. À medida que a cada dia novos produtos químicos são sintetizados, novos potenciais contaminantes podem aparecer nos corpos de água usados para abastecimento e, portanto, novas tecnologias de tratamento e restrições legais devem surgir, de modo a evitar que tais contaminantes possam vir a causar danos à saúde da população exposta.

Desse modo, a manutenção da qualidade da água tanto nos países desenvolvidos quanto nos países em desenvolvimento é um grande desafio, uma vez que diversos interesses políticos e 
comerciais acabam por competir e por vezes até inibir ações de preservação ambiental que levariam a uma melhora da qualidade e quantidade de água doce disponível, como no caso do uso de agrotóxicos em zonas de expansão agrária no Brasil, por exemplo.

\section{REFERENCIAS}

ALKHATIB, E.; PETERS, R. Wet weather impact on trihalomethane formation potential in tributaries to drinking water reservoirs, Environmental Monitoring and Assessment, Londres, v. 139, p.173-181, 2008.

ALMEIDA, E.; ASSALIN, M.R.; ROSA, M.A.; DURÁN, N. Tratamento de efluentes industriais por processos oxidativos na presença de ozônio. Química Nova, Brasília, v. 27, p.818-824, 2004.

ALMEIDA, F.V.; CENTENO, A.J.; BISINOTI, M.C.; JARDIM, W.F. Substâncias tóxicas persistentes (STP) no Brasil. Química Nova, Brasília, v. 30, p.1976-1985, 2007.

ANQUANDAH, G.A.K.; SHARMA, V.K.; PANDITI, V.R.; GARDINALI, P.R.; KIM, H.E.; OTURAN, M.A. Ferrate (VI) oxidation of propranolol: kinetics and products, Chemosphere, Amsterdam, v. 91, p.105-109, 2013.

ANVISA. Disponível em: www.anvisa.gov.br. Acessado em 15/03/2014

BATTALER, M.O.; FERNADEZ, L.A.; VELIZ, E. Eficiencia y sostenibilidad del empleo del ozono en la gestion de los recursos hidricos, Revista Internacional de Contaminacion Ambiental, Caracas, v. 26, p.85-95, 2010.

BEDDING, ND, MCINTYRE, AE, PERRY, R, LESTER, J.N. Organic contaminants in the aquatic environment I. Sources and occurrence. Science of the Total Environment, Amsterdam, v. 25, 143-67, 1982.

BELTRAN, F.J. Ozone-UV radiation-hydrogen peroxide oxidation technologies. In: Chemical Degradation Methods for Wastes and Pollutants, Berlim, p. 1-76, 2003.

BETANCOURT, W.Q.; ROSE, J.B. Drinking water treatment processes for removal of Cryptosporidium and Giardia, Veterinary parasitology, Amsterdam, v. 126, p.219-34, 2004.

BING-ZHI, D.; LIN, W.; NAI-YUN, G. The removal of bisphenol A by ultrafiltration, Desalination, Amsterdam, v. 221: p.312-17, 2008.

EPA - Environmental Protection Agency. Technologies and Costs Document for the Final Long Term 2 Enhanced Surface Water Treatment Rule and Final Stage 2 Disinfectants and Disinfection Byproducts Rule. EPA 815-R-05-013, 2005.

GRAHAM, N.; JIANG, C.; LI, X-Z.; JIANG, J-Q.; MA, J. The influence of pH on the degradation of phenol and chlorophenols by potassium ferrate. Chemosphere, Amsterdam, v. 56: p.949-56, 2004.

FAO. Disponível em: http://www.fao.org/water/en/. Acessado em 16/03/2014 
HEBERER, T. Occurrence, fate, and removal of pharmaceutical residues in the aquatic environment: a review of recent research data. Toxicology letters, Londres, v. 131, p. 5-17, 2002.

HEY, G.; GRABIC, R.; LEDIN, A.; ANDERSEN, H.R. Oxidation of pharmaceuticals by chlorine dioxide in biologically treated wastewater, Chemical Engineering Journal, Amsterdam, v. 185, p.236-42, 2012.

HOIGNÉ, J.; BADER, H. Kinetics of reactions of chlorine dioxide (OClO) in water - I. Rate constants for inorganic and organic compounds, Water Research, Amsterdam, v. 28, p.45-55, 1994.

HUBER, M.M.; GÖBEL, A.; JOSS, A.; HERMANN, N.; LÖFFLER, D.; MCARDELL, S.; RIED, A.; SIEGRIST, H.; TERNES, T.A.; VON GUNTEN, U. Oxidation of pharmaceuticals during ozonation of municipal wastewater effluents: a pilot study, Environmental Science \& Technology, Washington, v. 39, p.4290-4299, 2005.

LEE, Y.; von GUNTEN, U. Oxidative transformation of micropollutants during municipal wastewater treatment: Comparison of kinetic aspects of selective (chlorine, chlorine dioxide, ferrate (VI), and ozone) and non-selective oxidants (hydroxyl radical), Water Research, Amsterdam, v. 44: p.555-66, 2010.

LEZCANO, I.; REY, R.P.; BALUJA, C.E.; SÁNCHEZ, E. Ozone inactivation of Pseudomonas Aeruginosa, Escherichia Coli, Shigella Sonnei and Salmonella Typhimurium in water, Ozone-UV radiation-hydrogen peroxide oxidation technologies, Florida, v. 21, p. 293-300, 1999.

LEZCANO, I.; REY, R.P.; GUTIÉRREZ, M.S.; BALUJA, C.E.; SÁNCHEZ, E. Ozone inactivation of microorganisms in water: Gram positive bacteria and yeast, Ozone-UV radiation-hydrogen peroxide oxidation technologies, Flórida, v. 23, p.183, 2001.

LI, C.; LI, X.Z.; GRAHAM, N. A study of the preparation and reactivity of potassium ferrate, Chemosphere, Amsterdam, v. 61: p.537-43, 2005.

LOCATELLI, MAF, SODRÉ, F.F, JARDIM, W.F. Determination of Antibiotics in Brazilian Surface Waters Using Liquid Chromatography-Electrospray Tandem Mass Spectrometry. Archives of Environmental Contamination and Toxicology, Londres, v. 60: 385-93, 2011.

LOU, J-C. Generation of disinfection by-products (DBPs) at two advanced water treatment plants. Environmental Monitoring and Assessment, Amsterdam, v. 162: 365-75, 2010.

MEYER, S.T. O uso de cloro na desinfecção de águas, a formação de trihalometanos e os riscos potenciais à saúde pública. Caderno de Saúde Pública, Rio de Janeiro, v. 10: p.99-110, 1994.

MIERZWA, J.C., SILVA, M. C. C., RODRIGUES, L. D. B., HESPANHOL, I.; Tratamento de água para abastecimento público por ultrafiltração: avaliação comparativa através dos custos diretos de implantação e operação com os sistemas convencional e convencional com carvão ativado.

Engenharia Sanitaria e Ambiental, Brasília, v.13: p.78 - 87, 2008. 
MINISTERIO DAS CIDADES. Diagnóstico dos Serviços de Agua e Esgoto. 2013. 181 p. Disponível em: http://www.snis.gov.br/diagnostico-agua-e-esgotos/diagnostico-ae-2013. Acessado em: 24/09/2015.

MONTAGNER, C.C.; JARDIM, W.F. Spatial and seasonal variations of pharmaceuticals and endocrine disruptors in the Atibaia River, São Paulo State (Brazil). Journal of the Brazilian Chemical Society, Brasília, v. 22: p.1452-62, 2011.

PÁDUA, V.L. Remoção de micro-organismos emergentes e microcontaminantes orgânicos no tratamento de água para consumo humano. $1^{\text {a }}$ Ediçao. Ed. ABES, Rio de Janeiro , 2009, 394 p.

PASCHOALATO, C.F.P.R.; TRIMAILOVAS, M.R; BERNARDO, L.D. Formation of halogenated organic byproducts using preoxidation with chlorine, ozone and peroxone and post-chlorination of water containing humic substances, Engenharia Sanitaria e Ambiental, Brasília, v.13: p.313-22, 2008.

PLEITER, M.G.; GONZALO, S.; PALOMARES, I.R.; LEGANÉS, F.; ROSAL, R.; BOLTES, K.; MARCO, E.; PIÑAS, F.F. Toxicity of five antibiotics and their mixtures towards photosynthetic aquatic organisms: implications for environmental risk assessment. Water Research, Amsterdam, v. 47: p.2050-2064, 2013.

QUEK, P.H.; JIANG, Y.H. Indicators for photoreactivation and dark repair studies following ultraviolet disinfection, Journal of Industrial Microbiology \& Biotechnology, Amsterdam, v. 35: p. $533-41,2008$.

ROSENFELDT, E.J. UV Advanced Oxidation Treatment of Emerging Contaminants in Drinking and Reuse Water, In 2011 Ohio Section AWWA 73rd Annual Conference Handouts, Ohio, v. 73, p.1-13, 2011.

SHARMA, V.K. Ferrate (VI) and ferrate (V) oxidation of organic compounds: Kinetics and mechanism. Coordination Chemistry Reviews, Washington, v. 257: p.495-510, 2013.

SHARMA, V.K.; LIU, F.; TOLAN, S.; SOHN, M.; KIM, H.; OTURAN, M.A. Oxidation of $\beta$ lactam antibiotics by ferrate (VI), Chemical Engineering Journal, Amsterdam, v. 221: p.446 $451,2013$.

SODRÉ, F.F. Fontes Difusas de Poluição da Água: Características e métodos de controle. Artigos Temáticos do AQQUA, São Paulo, v. 1: p.9-16, 2012.

STACKELBERG, P.E.; GIBS, J., FURLONG, E. T., MEYER, M. T., ZAUGG, S. D., LIPPINCOTT, R. L. Efficiency of conventional drinking-water-treatment processes in removal of pharmaceuticals and other organic compounds. Science of the Total Environment, Amsterdam, v. 377: p.255-72, 2007.

TEIXEIRA, JC, PUNGIRUM, M.E.M.C. An analysis of the relationship between health and sanitation in Latin America and the Caribbean, using secondary data from PAHO - The Pan American Health Association. Revista Brasileira de Epidemiologia, Brasília, v. 8: 365-76, 2005. 
TIAN, C.; LIU, R.; LIU, H.; QU, J. Desinfection by-products formation and precursors transformation during chlorination and chloramination of highly-polluted source water: significance of ammonia, Water Research, Amsterdam, v. 47: p.5901-10, 2013.

TOMPECK, M.A.; JONES, P.H. Water Treatment In: Encyclopedia of Environmental Science and Engineering. 5a. Edição, v. 2, 2006. 817 p.

WOLFE, R.L. Ultraviolet disinfection of potable water, Environmental Science \&

Technology, Washington, v. 24: p.768-73, 1990.

World Health Organization. Guidelines for Drinking-water Quality, 4a. Ed, 2011. 564 p.

YANG, B.; YING, G.G.; ZHAO, J.L.; LIU, S.; ZHOU, L.J.; CHEN, F. Removal of selected endocrine disrupting chemicals (EDCs) and pharmaceuticals and personal care products (PPCPs) during ferrate(VI) treatment of secondary wastewater effluents. Water Research, Amsterdam, v. 46: p.2194-2204, 2012.

ZHOU, H.; SMITH, D.W. Advanced technologies in water and wastewater treatment. Canadian Journal of Civil Engineering, Ottawa, v. 28: p.49-66, 2001. 